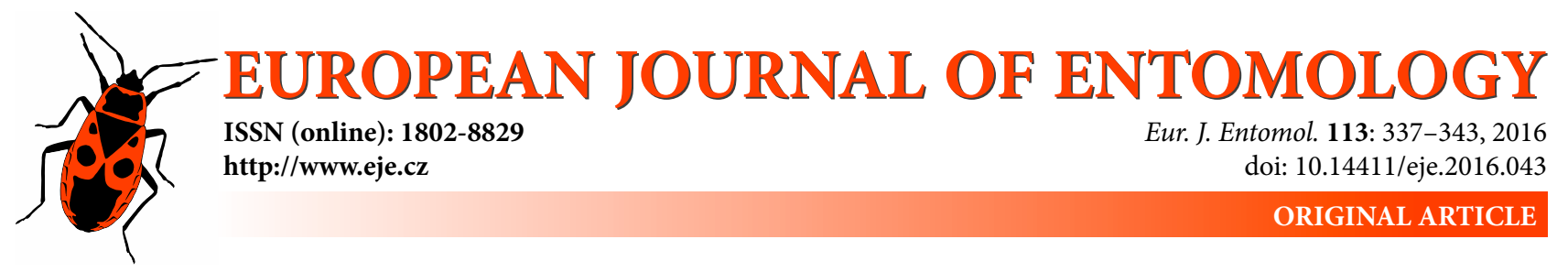

\title{
Northern geometrid forest pests (Lepidoptera: Geometridae) hatch at lower temperatures than their southern conspecifics: Implications of climate change
}

\author{
JuLIA FÄLT-NARDMANN ${ }^{1,2}$, TERO KLEMOLA ${ }^{1}$, MECHTHILD ROTH $^{2}$, KAI RUOHOMÄKI $^{1}$ and KARI SAIKKONEN ${ }^{3}$ \\ ${ }^{1}$ Section of Ecology, Department of Biology, University of Turku, FI-20014 Turku, Finland; e-mails: julia.falt@utu.fi, \\ tero.klemola@utu.fi, kai.ruohomaki@utu.fi \\ ${ }^{2}$ Professur für Forstzoologie, Technische Universität Dresden, Tharandt, Germany; e-mail: mroth@forst.tu-dresden.de \\ ${ }^{3}$ Management and Production of Renewable Resources, Natural Resources Institute Finland (Luke), Turku, Finland; \\ e-mail: kari.saikkonen@luke.fi
}

\begin{abstract}
Key words. Lepidoptera, Geometridae, Epirrita autumnata, Erannis defoliaria, Operophtera brumata, climate change, hatching, Northern Europe, phenology, photoperiod, synchrony, temperature sum
\end{abstract}

\begin{abstract}
Climate change may facilitate shifts in the ranges and the spread of insect pests, but a warming climate may also affect herbivorous insects adversely if it disrupts the locally adapted synchrony between the phenology of insects and that of their host plant. The ability of a pest species to colonize new areas depends on its ability to adjust the timing of phenological events in its life cycle, particularly at high latitudes where there is marked seasonality in temperature and day length. Here we incubated eggs of three species of geometrid moth, Epirrita autumnata, Operophtera brumata and Erannis defoliaria from different geographical populations (E. autumnata and O. brumata from Northern Finland, E. autumnata and E. defoliaria from Southern Finland and all three species from Germany) in a climate chamber at a constant temperature to determine the relative importance of geographic origin in the timing of egg hatch measured in terms of cumulative temperature sums (degree days above $5^{\circ} \mathrm{C}$, DD5); i.e. the relative importance of local adaptation versus phenotypic plasticity in the timing of egg hatch. In all three species, eggs from northern populations required a significantly lower temperature sum for hatching than eggs from southern populations, but the differences between them in temperature sum requirements varied considerably among species, with the differences being largest for the earliest hatching and northernmost species, E. autumnata, and smallest for the southern, late-hatching E. defoliaria. In addition, the difference in hatch timing between the $E$. autumnata eggs from Southern Finland and Germany was many times greater than the difference between the two Finnish populations of $E$. autumnata, despite the fact that the geographical distances between these populations is similar. We discuss how these differences in hatching time may be explained by the differences in hatch-budburst synchrony and its importance for different moth species and populations. We also briefly reflect on the significance of photoperiod, which is not affected by climate change. It is a controller that works parallel or in addition to temperature sum both for egg hatch in moths and bud burst of their host plants.
\end{abstract}

\section{INTRODUCTION}

Predicted and recorded range shifts and spread of agricultural and forest insect pests due to climate change is a cause of concern (Battisti \& Larsson, 2015). This unfortunately can not be dismissed as unfounded, as pest species arriving in new areas have repeatedly been reported causing significant environmental and economic losses (Lodge, 1993; Cannon, 1998; Pimentel et al., 2000).

Because environmental factors play a crucial role in the performance of many pests, climate change can facilitate invasions of pests by rendering new areas similar enough to the original distribution range of the pest species (Vänninen et al., 2011). Successful range expansion across latitudes, particularly at high latitudes, requires that species are able to use local temperature and/or day length as cues to coordinate their phenology and synchronize their life cycles with individuals and species they interact with (Danks, 1987; Valtonen et al., 2011; Saikkonen et al., 2012). For example, in order to synchronize the life cycles of herbivorous insects with the optimal nutritional phase of their host plants the hatching of their eggs needs to be triggered by a certain combination of day length and accumulated temperature sum (van Asch \& Visser, 2007). Whether this synchrony, resulting from local adaptation, can be adjusted to ensure a successful life cycle in new environments, both in geographically new areas that the species may colonize and in response to changing conditions in its original range, depends on whether there is sufficient phenotypic plasticity to reach or maintain synchrony. 
The synchrony between moth egg hatching and budburst in spring has been extensively studied in Northern Europe in two spring-feeding univoltine geometrids, the autumnal moth, Epirrita autumnata (Borkhausen), and the winter moth, Operophtera brumata (Linnaeus) (Tenow, 1972; Buse \& Good, 1996; Bylund, 1999; Visser \& Holleman, 2001; Jepsen et al., 2011). In northern Fennoscandia, the larvae of both species are highly dependent on young leaves of mountain birch, Betula pubescens ssp. czerepanovii (Tenow, 1972; Bylund, 1999). In this study, the topic is expanded to include latitudinal differences and local adaptations in egg hatch timing of geographically different populations of the above mentioned species and a third spring-feeding geometrid, the mottled umber, Erannis defoliaria (Clerck).

Epirrita autumnata is a common and widely distributed Holarctic species (Tenow, 1972; Tammaru et al., 2001) while $O$. brumata occurs naturally in most of Europe, but has also been introduced into North America (Embree, 1966; Gillespie et al., 1978; Tenow et al., 2013). Erannis defoliaria is also widely spread in Eurasia, but the species is not as cold-hardy and does not occur as far north as the other two species (Ammunét et al., 2012). Epirrita autumnata and O. brumata display cyclic population dynamics with outbreaks, the former species especially in the northern parts of its distribution and the latter throughout its distribution (Tenow, 1972; Bylund, 1999; Ruohomäki et al., 2000; Tenow et al., 2013). The population dynamics of $E$. defoliaria have yet to be studied in detail in order to confirm that its population dynamics is similar. During outbreaks, larvae of all species, which are polyphagous defoliators of deciduous trees and shrubs, may cause severe damage in forests and in the case of $O$. brumata and $E$. defoliaria, orchards, gardens and parks (Holliday, 1977; Tomiczek \& Perny, 2005). Unlike the females of E. autumnata those of both $O$. brumata and $E$. defoliaria are flightless, but the larvae of all species are capable of ballooning, i.e. they use thin strands of silk to carry them aloft and air born dispersal to move between locations (Edland, 1971; Bylund, 1999; Bell et al., 2005; Glavendekić, 2010).

We determined whether eggs of moths from different locations hatch synchronously with each other when incubated under the same laboratory conditions, or whether the hatch times differ. We compared the results for the three species studied with each other in order to determine whether the magnitude of the differences are similar between species. Based on the results we hypothesize that climate change in relation to the differences in temperature sum of egg hatch and photoperiod requirements may have implications for potentially invasive pests.

\section{MATERIAL AND METHODS}

\section{Experimental methods}

To test the relative importance of the geographic origin of the populations studied on the timing of egg hatch, eggs of different origins were incubated under the same climatic conditions until they hatched.

Epirrita autumnata eggs were obtained from four females collected in the wild in Germany (Dresden, WGS84: $51^{\circ} 8^{\prime} \mathrm{N}$,

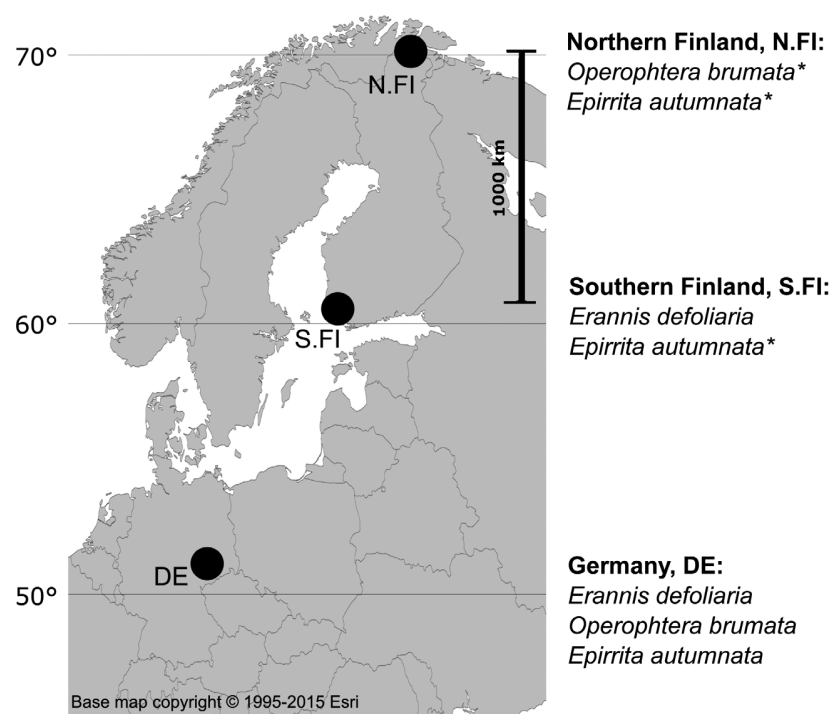

Fig. 1. Origins of the populations used in this research. Eggs of the two test groups, with one week between the start of the experiments, were sampled from the populations marked with an asterisk $\left.{ }^{*}\right)$. From the other populations only one test group was sampled.

$\left.13^{\circ} 42^{\prime} \mathrm{E}\right)$ in the autumn of 2012 and from twelve females collected as larvae in Southern Finland $\left(60^{\circ} \mathrm{N}\right)$ and fifteen females from a northern $\left(69^{\circ} \mathrm{N}\right)$ laboratory strain in Finland (Fig. 1). Eggs of $O$. brumata were obtained from fifteen females collected in Germany and ten females from a northern laboratory strain in Finland. The laboratory strains of E. autumnata and O. brumata have routinely been complemented with wild individuals. Only two egg-laying females of $E$. defoliaria were found and collected in southern Finland (Turku, $60^{\circ} 26^{\prime} \mathrm{N}, 22^{\circ} 10^{\prime} \mathrm{E}$ ) and four in Germany.

The females were kept outdoors individually in plastic jars and given twigs or tightly rolled and tied pieces of tissue paper as a substrate for egg-laying. All the eggs laid by the German females were stored outdoors in the vicinity of their respective areas of origin until mid-December when they were transferred to $-5^{\circ} \mathrm{C}$. The Finnish $E$. autumnata and $O$. brumata eggs were stored in a laboratory at +1 to $-4^{\circ} \mathrm{C}$ and the Finnish $E$. defoliaria eggs outdoors in Finland until the end of December when they were first transported on an ice brick to Germany by plane and there transferred to $-5^{\circ} \mathrm{C}$.

In April 2013, eggs from all seven populations were randomly (clearly flattened or discoloured eggs were not included) assigned to one of three replicates of 15 eggs each. The German O. brumata replicates and the E. autumnata replicates from Northern Finland all contained one egg from each female. In the other cases, eggs from less than fifteen females were available and the replicates consisted of an even mix of eggs from the different females. The eggs of one female commonly hatch synchronously within one to three days, although the range depends on temperature ( $\mathrm{T}$. Klemola, pers. obs.). The eggs, contained in closed $30 \mathrm{ml}$ glass bottles, were placed in a constant climate chamber (Binder KBF 720) on $16^{\text {th }}$ of April. Additional sets of three replicates of the Finnish E. autumnata and $O$. brumata populations were placed in this chamber six days later, on $22^{\text {nd }}$ of April.

The temperature in the climate chamber was set weekly to match an average temperature for that week calculated from temperatures measured in 2008-2012 at the weather station in Southern Finland (Artukainen, Turku: $60^{\circ} 27^{\prime} \mathrm{N}, 22^{\circ} 10^{\prime} \mathrm{E}$ ). Daylight fluorescent tubes (two Narva BIO vital LT 21W T5-EQ/958 and one Narva BIO vital LT 14W T5-EQ/958) were mounted in 


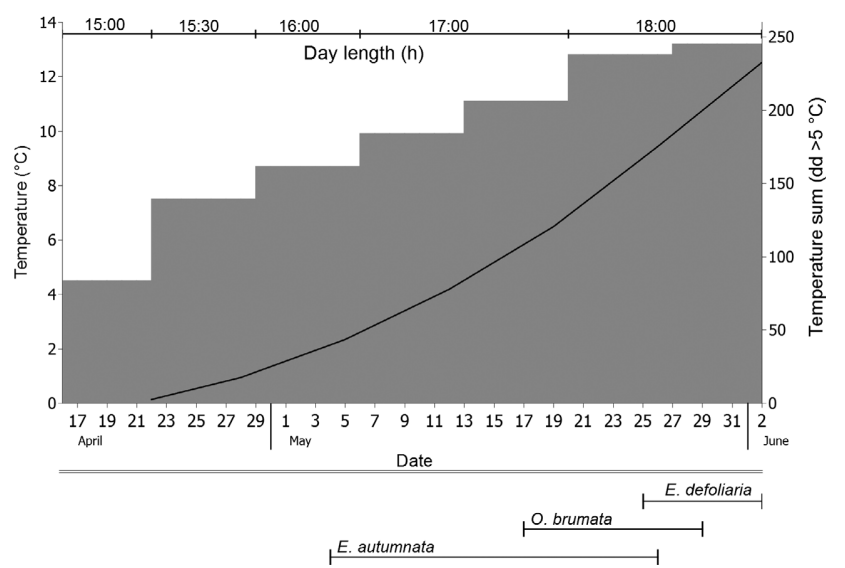

Fig. 2. Environmental conditions in the constant climate chamber preceding and during egg hatch. The grey area shows the temperatures $\left({ }^{\circ} \mathrm{C}\right)$ and the black curve the temperature sum accumulated above $5^{\circ} \mathrm{C}\left(\mathrm{dd}>5^{\circ} \mathrm{C}\right)$. The segmented line above the grey temperature area shows the day length $(h)$. The black lines below the graph correspond with hatching periods of each of the species of moth (results for all populations pooled).

the chamber and timed to follow the weekly average sunrise and sunset times in southern Finland, rounded to the nearest half hour.

Larvae were counted and removed from the bottles daily except on three occasions. Larvae that eclosed between 4- $6^{\text {th }}$ of May (eight E. autumnata larvae) were counted on the $6^{\text {th }}$ of May, and as it was not possible to tell on which of the three days they had eclosed they were divided between the three dates for the statistical analyses (three larvae for $4^{\text {th }}$ and $5^{\text {th }}$ of May and two for $6^{\text {th }}$ of May). In the same manner, larvae eclosed on $25^{\text {th }}$ or $26^{\text {th }}$ of May and $1^{\text {st }}$ or $2^{\text {nd }}$ of June were divided equally between the two dates. Later, the same statistical analyses were additionally run on a dataset where all the larvae were assumed to have eclosed on the day when they were counted ( $6^{\text {th }}$ and $26^{\text {th }}$ of May and $2^{\text {nd }}$ of June $)$. However, the changes in the results were negligible.

\section{Statistical analysis}

We analyzed egg hatch timing in relation to temperature in a constant climate chamber. For this, egg-hatch times were measured in degree-days (DD), i.e. a cumulative sum of daily average temperatures exceeding a certain base level, in this case $5^{\circ} \mathrm{C}$. The measurements started on the day when the eggs were transferred into the climate chamber, but the base level was first reached some days later (Fig. 2). The five degrees Celsius threshold (DD5) is commonly used in botany and horticulture to mark the onset of the growing season (for example Pöyry et al., 2009).

Statistical analyses were conducted separately for each geometrid species. As additional sets of eggs of Finnish E. autumnata and $O$. brumata were placed in the climate chamber one week later than the other eggs, the timing of the start of the experiment ("early" or "late") was merged with origin of population into one fixed factor with five levels. This yielded, for example, "eggs from Northern Finland placed into the chamber early" and "eggs from Northern Finland placed into the chamber late" as two separate groups for the analysis. The German eggs were all treated as "early".

We used linear mixed models with temperature sum at hatching as a response variable, and origin of the population merged with the timing of the experiment as a fixed explanatory variable. Bottle replicate was set as a random factor and the variation it accounted for was tested using a likelihood-ratio test (LRT). Assumptions for the models were checked using the residuals. Inequality of variance among populations was accounted for by enabling between-subject heterogeneity for $O$. brumata and $E$. defoliaria but not for E. autumnata, as a corresponding model did not converge for this species. To facilitate accurate F-tests, the Kenward-Roger method was used for calculating the standard error and denominator degrees-of-freedom of the fixed effect. All analyses were done using the GLIMMIX procedure in SAS v. 9.4 (SAS Institute Inc., Cary).

\section{RESULTS}

The percentage of eggs that hatched was high in all three species (E. autumnata $83.1 \%$, O. brumata $81.5 \%$ and $E$. defoliaria $94.4 \%$ ). However, it is worth noting that clearly discoloured or flattened eggs were not included in this experiment. The total hatching period extended from $4^{\text {th }}$ of May (39.7 dd) to $2^{\text {nd }}$ of June (232.4 dd) (Fig. 2).

The population merged with the experiment timing was a highly significant fixed factor in the model for all three species (E. autumnata: $\mathrm{F}_{4,9.40}=1240.5 ; \mathrm{p}<0.0001$, O. brumata: $\mathrm{F}_{2,8.99}=132.0 ; \mathrm{p}<0.0001$, E. defoliaria: $\mathrm{F}_{1,20.72}=$ $67.1 ; \mathrm{p}<0.0001)$. The replicate as a random factor was not statistically significant for any of the species $(p>0.1$ in all LRTs).

The eggs from southern populations of all three species required a higher temperature sum for hatching than those from northern populations (Fig. 3). In all cases, the difference was statistically significant. However, the differences between the differently timed sets of eggs of E. autumnata and $O$. brumata were also significant, with the eggs placed in the constant climate chamber a week later requiring larger temperature sums for hatching, although the differences in temperature sums were smaller than for those from different geographical locations.

The differences between the populations in temperature sum requirements differed considerably among the species (Fig. 3). The difference between E. autumnata eggs from Germany and Southern Finland ("early") was 78.3 DD5, but for $E$. defoliaria the same difference was only 18.1 DD5. The situation was the same when populations from Germany and Northern Finland were compared, with the difference for E. autumnata $84.8 \mathrm{DD} 5$ and O. brumata only 43.2 DD5.

\section{DISCUSSION}

For all three species of moth studied, eggs from northern populations required lower temperature sums for hatching than those from southern populations (Fig. 3). A similar pattern has been observed earlier for O. brumata (Speyer, 1938; Wylie, 1960). However, Hibbard \& Elkinton (2015) did not find any such differences between introduced $O$. brumata populations on Vancouver Island and in Massachusetts in North America. The pattern recorded might be an adaptation to match larval eclosion with bud burst of host trees, a critical synchrony for many spring folivores (Visser \& Holleman, 2001; van Asch \& Visser, 2007), with trees from high-latitude populations frequently requiring a lower temperature sum for flushing in spring than their southern conspecifics (Worrall \& Mergen, 1967; Myking $\&$ Heide, 1995). Southern moth species spreading northwards would be subject to the risk of a mismatch between budburst and egg hatching in spring unless they can adapt 

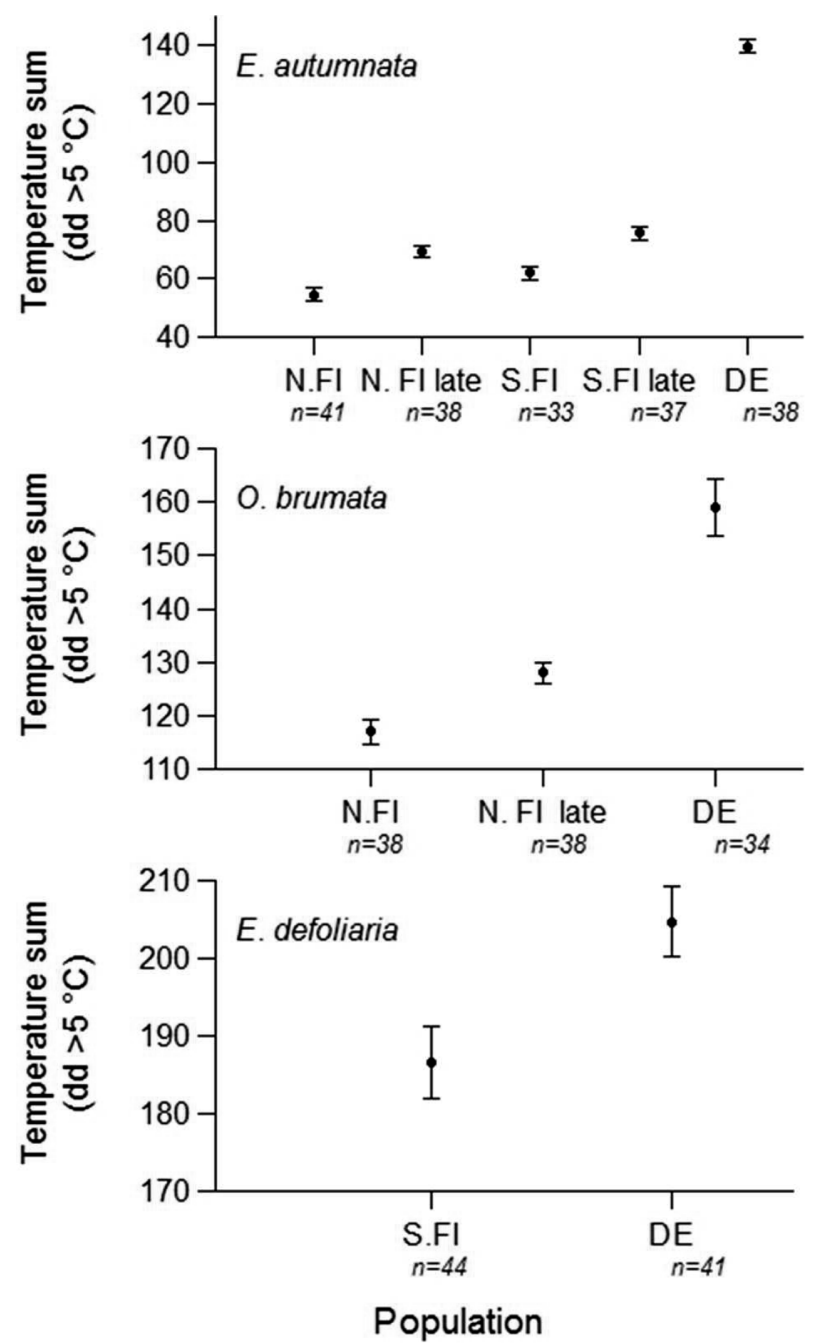

Fig. 3. Model-derived marginal mean estimates with 95\% confidence limits for accumulated temperature sums (dd $>5^{\circ} \mathrm{C}$ ) at egg hatch. N.FI and S.FI stand for Northern and Southern Finland, respectively, and DE for Germany. The attribute "late" indicates that the eggs were transferred to the constant climate chamber one week later than the other eggs. Note the different scales of the $y$-axes. All groups differ (at $\alpha=0.05$ ) significantly from all other groups in pairwise comparisons.

to hatch at a lower temperature sum (Tikkanen et al., 2006; Saikkonen et al., 2012). Even if temperatures increase due to global climate change, the relationship between budburst and egg hatch would remain the same, although both events would occur earlier in spring.

However, other environmental cues, most importantly day length, which is unaffected by climate change, may play an important role in both phenological events. Photoperiod is known to affect the timing of bud burst in, for example, white birch, Betula pubescens (Caffarra et al., 2011a, b), the main host of both E. autumnata and $O$. brumata in northern Fennoscandia. It is also an important controller of life cycle events in many moth species, either alone or acting together with temperature (Danks, 1987; Valtonen et al., 2011). Thus the matching of bud burst and hatching of geometrid eggs in a changing climate depends on the extent to which herbivores and their host plants use the same environmental cues for timing their phenology in spring. In fact, both trees and moths are likely to rely on a sophisticated combination of environmental cues for their development, with day length taken into account only when certain temperature requirements are already met or the reverse. The previous winter and autumn temperatures would then count towards the accumulating temperature sum in addition to the conditions in spring (Kaitaniemi \& Ruohomäki, 1999; Visser \& Holleman, 2001; Bale et al., 2002; Valtonen et al., 2011). There is also evidence that not only the temperatures above a certain development threshold count, but that a "chilling sum" of accumulating cold temperatures and the length of the sub-zero chilling period is also important (Kimberling \& Miller, 1988; Visser \& Holleman, 2001; Hibbard \& Elkinton, 2015). A rise in temperatures could affect these combinations of control mechanisms in a number of ways, with, for example, day length becoming a new primary trigger or restrictor for phenological events if the temperature requirements are practically always met. An understanding of which combinations of environmental cues are relevant for triggering phenological events in both plants and their insect pests is crucial when making predictions of future distributional ranges of insect pests and the damage they will cause.

The recorded latitudinal difference in hatch timing is unlikely to be explained by size differences between eggs of northern and southern origins. Although eggs were not measured in this experiment, a previous analysis of data on egg size and time to egg hatch for E. autumnata did not yield any correlations [K. Ruohomäki, unpubl.; but see Ruohomäki et al. (1993), in this experiment the effect of egg size on hatch timing, however, cannot be distinguished from that of the order in which the eggs were laid]. In either case, local differences in egg-size are more likely to be only a proximate cause of hatch timing, a mechanism for achieving an optimal synchrony in spring at different locations.

Although Kimberling \& Miller (1988) show that at least $O$. brumata eggs from Oregon, USA start accumulating a temperature sum in mid-January, we cannot entirely rule out the possible effects of differences in conditions the eggs experienced in storage in the autumn, which may provide an explanation for differences in egg hatch timing in the different populations. The German eggs were stored outdoors and the Finnish ones in a laboratory. Because autumnal moth eggs start accumulating a temperature sum for hatching before the onset of winter (Kaitaniemi \& Ruohomäki, 1999), it is possible that the experimental eggs accumulated different heat sums in the autumn. This may have affected the results in two opposite ways. Firstly, the German eggs could have acquired a head start, as the outdoor temperatures that they experienced were at least temporarily higher than those the Finnish eggs experienced in the laboratory. If anything, this should have lowered the temperature sum requirements of the German eggs in spring, in which case the results, had the eggs been stored in identical conditions, should show an even more extreme difference in hatch timing between Finnish and German eggs than was recorded. Secondly, the German eggs may 
have experienced fewer chilling days than the Finnish eggs. Previous studies show, that the longer the period moth eggs experience chilling is, the lower temperature sums the eggs require in spring for hatching (Kimberling \& Miller, 1988; for E. autumnata, K. Ruohomäki, pers. observ.). If the chilling period had been similar for all eggs used in this study, the difference in hatching time between German and Finnish eggs might have been smaller.

The temperature sum requirements of the three species of moth differ considerably. Erannis defoliaria, the species which has the most southern range and which hatches later than the other two species, had a relatively small difference in hatch timing between the two test populations, whereas for the northernmost species, the early hatching E. autumnata, there were large differences in hatch timing between the Finnish and German populations (Fig. 3). This may reflect different host-larva relationships in the different species, with some species being more flexible in the use of various host plants or the synchrony between budburst and egg hatch being more critical for some species than others. The number of available host plant species and host plants at different stages of leaf development is in general larger in the south than in the north. Southern polyphagous folivores may thus not be at as great a risk as northern species of not being synchronized with any one host plant, as there will always be something suitable to eat, especially if the eggs hatch late in spring when practically all the plants have started flushing. The southernmost species studied, $E$. defoliaria, also has slightly larger eggs and neonate larvae than the other two species and hence perhaps is also able to process older and tougher leaf material after hatching.

From the above discussion, it is evident that while our results indicate that the eggs of northern moths hatch at a lower temperature sum than those of southern moths in all three geometrid species studied, it is not possible to make a simple generalization concerning latitudinal clines in temperature sum requirements for egg hatch, as the magnitude of the differences differ greatly between species.

In our experiment, E. autumnata eggs from northern Finland hatched earlier than those of $O$. brumata from the same area (54.5 DD5 vs. 117.0 DD5, Fig. 3). As the larvae of both species primarily feed on Betula pubescens ssp. czerepanovii in Northern Finland, the eggs should hatch at the same time if both species are dependent on the same developmental phase of the host leaves. Mjaaseth et al. (2005) report that of larvae that originate from northern Norway those of E. autumnata are one instar ahead of those of $O$. brumata in development and attribute this to the faster development of early instar larvae of E. autumnata. However, a difference of about one week in egg hatch and one instar in larval development between E. autumnata and $O$. brumata has been also routinely recorded in our experiments in northern Finland, and Jepsen et al. (2011) show that there is a difference in the egg hatch times of $E$. autumnata and O. brumata. Synchrony between $O$. brumata and its various host plants, ranging from broad leaved species, such as mountain birch, apple (Malus domestica) and oak (Quercus robur) to sitka spruce (Picea sitchensis) and common heather (Calluna vulgaris), has been extensively studied (Holliday, 1977; Kerslake \& Hartley, 1997; van Dongen et al., 1997; Bylund, 1999; Visser \& Holleman, 2001; Tikkanen \& Lyytikäinen-Saarenmaa, 2002). These studies highlight in an exemplary way the variability in hatch-budburst synchrony and consequently its varying importance even for different, highly local populations of the same species of moth. It may well be that synchronizing egg hatch with the youngest mountain birch leaves is more important for E. autumnata than O. brumata, or that $O$. brumata larvae actually prefer slightly larger birch leaves, as they feed on leaves that are loosely spun together with silk (Tenow, 1972).

Interestingly, E. autumnata, the only species for which we studied eggs from all three geographical populations, has small differences between the S.FI and N.FI populations in temperature sum at hatching, but a much larger difference between the S.FI and DE populations (6.5 DD5 vs. 78.3 DD5, Fig. 3). However, in spring, the differences in temperature sum accumulation and, for example, photoperiod are greater between the two Finnish locations than between southern Finland and Germany. While the result may at least partly be due to the different conditions at which the eggs of the different populations were stored, as discussed above, we can suggest at least two biological explanations for this unexpected pattern. First, it could simply reflect differences in the evolution and distributional histories of the three populations. The Central European and Finnish E. autumnata populations may have separated from each other a long time ago, with the Finnish population later spreading gradually northwards and consequently having less time to diversify. Even if the species may have been present in all three locations for equally long periods, there may be more genetic exchange between the two geographical ends of the continuous E. autumnata population within Finland than between the Central European and Finnish populations separated by the Baltic Sea, even though the distance between the southern and northern Finnish location is roughly the same as the distance between the southern Finnish and German location (Fig. 1). Second, the highly polyphagous $E$. autumnata may feed on a different set of host plants in Central Europe than in Finland and may synchronize its egg hatch to match the phenology of the dominant host plant at both these locations.

The difference in temperature sum required for hatching of the "early" eggs and eggs placed in climatic chamber one week later is consistent with previous studies showing that the classical $+5^{\circ} \mathrm{C}$ base temperature for the botanical growing season may not be a biologically relevant threshold for the development of moth eggs, at least not for all moth species, and perhaps especially not for species feeding on newly-flushed foliage in spring (Embree, 1970; Kimberling \& Miller, 1988; Valtonen et al., 2011). In our experiment, both "early" and "late" eggs were transferred to the constant climate chamber while temperatures were still below $+5^{\circ} \mathrm{C}$ and they should have accumulated similar temperature sums above that temperature. However, in both E. autumnata and O. brumata the early eggs hatched 
before the late ones, indicating that they had already started to develop before the temperatures reached $+5^{\circ} \mathrm{C}$. Embree (1970) and Kimberling \& Miller (1988) report that the developmental threshold of $O$. brumata is $3.9^{\circ} \mathrm{C}$ and $4^{\circ} \mathrm{C}$ respectively in Nova Scotia, Canada and Oregon, USA, while that of $O$. brumata eggs in northern Norway is as low as $1.4^{\circ} \mathrm{C}$ (Jepsen et al., 2011) and E. autumnata eggs from northern areas may resume development in spring when the temperatures are still below zero (Nilssen \& Tenow, 1990).

Interestingly, Kimberling \& Miller (1988) show that the duration of the chilling period, during which the eggs were exposed to $1{ }^{\circ} \mathrm{C}$, not only affected the temperature sum accumulation over a certain development threshold required for hatching, but also the threshold itself. In their experiment eggs experiencing a long chilling period had a lower development threshold than eggs with a short chilling period. Based on this result and the variation between $1.4^{\circ} \mathrm{C}$ and $4^{\circ} \mathrm{C}$ reported as the development thresholds for $O$. brumata it can be assumed that moth eggs from northern populations experiencing long winters have lower development thresholds than populations in areas with a less severe winter. Following Kimberling \& Miller (1988), the development threshold is however not intrinsically determined by the average conditions experienced by the population in the past but the temperatures they are currently exposed to. Thus eggs from different populations that are exposed to the same environmental conditions should have the same development threshold, and our results for eggs originating from different geographical locations but kept under similar environmental conditions should be comparable with each other in terms of temperature sum accumulation, although the actual number of degree days at hatching would be different if another threshold temperature is used.

Yet another possible mechanism underlying latitudinal differences in development and hatch timing - in addition to northern eggs requiring lower temperature sums for hatching or alternatively having a lower development threshold altogether - would be variation in the thermal reaction norm of geographically different populations. It is possible that the embryos of individuals from northern populations develop faster than those from southern populations, especially at colder temperatures (van Doorslaer \& Stoks, 2005). In other words, there could be local adaptation in speed of development as well as in the increase of speed of development with increase in temperature. However, based on our results it is impossible to distinguish between the potential proximate mechanisms, or likely their combinations, that would result in moth eggs from northern populations hatching earlier than those of southern origin.

We conclude that the temperature sum requirements for egg hatch differ, not only between the three species of moth studied, but also between southern and northern populations of the same species. The differences are not similar between species and do not necessarily change linearly with latitude, but may reflect different evolutionary and distributional histories or different host plant prefer- ences of the local populations, although differences in the conditions in which the eggs were stored in autumn may also have influenced the results recorded in this study. We argue that rising temperatures due to climate change affect host-insect pest relationships differently depending on what environmental cues the species use to control their phenology in spring. It is recommended that this is taken into account when predicting insect range expansions and pest damage in a changing climate. Further experiments carried out under controlled laboratory conditions and in the field are being done using the same and additional species of moth to further investigate the role of temperature and photoperiod, both acting independently and together, on not only egg hatch but also other life cycle events of forest insect pests.

ACKNOWLEDGEMENTS. We sincerely thank T. Andersson, R. Einspender, K. Fält, A. Karhilahti, T. Pajari and A. Teräs for their help with collecting geometrid females and eggs for this research and A. Solger and T. Stahl for their valuable help in the laboratory. We are grateful to $\mathrm{H}$. Ojanen for his help with maps, for E. Nyman for reviewing the language of this manuscript and for I. Brunk and three anonymous reviewers for their feedback and comments on the manuscript. We warmly thank P. Niemelä for insightful suggestions and invaluable support at every step of the research and writing process. Meteorological data for this study was obtained from the Finnish Meteorological Institute and the Chair of Meteorology at the Technische Universität Dresden, and data on photoperiod and day length from the Helsinki University Almanac Office. This study was funded by the Entomological Society of Finland, Finnish Cultural Foundation, TOP-foundation and Turku University Foundation (grants to J.F-N.).

\section{REFERENCES}

Ammunét T., Kaukoranta T., Saikkonen K., Repo T. \& Klemola T. 2012: Invading and resident defoliators in a changing climate: cold tolerance and predictions concerning extreme winter cold as a range-limiting factor. - Ecol. Entomol. 37: 212-220.

Bale J.S., Masters G.J., Hodkinson I.D., Awmack C., Bezemer T.M., Brown V.K., Butterfield J., Buse A., Coulson J.C. \& FARRAR J. 2002: Herbivory in global climate change research: direct effects of rising temperature on insect herbivores. Glob. Chang. Biol. 8: 1-16.

Battisti A. \& Larsson S. 2015: Climate change and insect pest distribution range. In Björkman C. \& Niemelä P. (eds): Climate Change and Insect Pests. CABI, Wallingford, pp. 1-15.

Bell J.R., Bohan D.A., Shaw E.M. \& Weyman G.S. 2005: Ballooning dispersal using silk: world fauna, phylogenies, genetics and models. - Bull. Entomol. Res. 95: 69-114.

Buse A. \& Good J.E.G. 1996: Synchronization of larval emergence in winter moth (Operophtera brumata L.) and budburst in penduculate oak (Quercus robur L.) under simulated climate change. - Ecol. Entomol. 21: 335-343.

Bylund H. 1999: Climate and the population dynamics of two insect outbreak species in the north. - Ecol. Bull. 47: 54-62.

Caffarra A., Donnelly A., Chuine I. \& Jones M.B. 2011a: Modelling the timing of Betula pubescens budburst: I. Temperature and photoperiod: a conceptual model. - Clim. Res. 46: 147-157.

Caffarra A., Donnelly A. \& Chuine I. 2011b: Modelling the timing of Betula pubescens budburst: II. Integrating complex effects of photoperiod into process-based models. - Clim. Res. 46: $159-170$. 
CANNON R.J.C. 1998: The implications of predicted climate change for insect pests in the UK, with emphasis on non-indigenous species. - Glob. Chang. Biol. 4: 785-796.

Danks H.V. 1987: Insect Dormancy: An Ecological Perspective. Biological Survey of Canada (Terrestrial Artropods), Ottawa, $439 \mathrm{pp}$.

EdLAND T. 1971: Wind dispersal of the winter moth larvae Operophtera brumata L. (Lep., Geometridae) and its relevance to control measures. - Nor. Entomol. Tidsskr. 18: 103-107.

EMBREE D. 1966: The role of introduced parasites in the control of the winter moth in Nova Scotia. - Can. Entomol. 98: 11591168 .

EMBREE D. 1970: The diurnal and seasonal pattern of hatching of winter moth eggs, Operophtera brumata (Geometridae: Lepidoptera). - Can. Entomol. 102: 759-768.

Gillespie D.R., Finlayson T., Tonks N.V. \& Ross D.A. 1978: Occurrence of the winter moth, Operophtera brumata (Lepidoptera: Geometridae), on southern Vancouver Island, British Columbia. - Can. Entomol. 110: 223-224.

GLAVENDEKIĆ M., 2010: Parasitoids and hyperparasitoids of Erannis defoliaria $\mathrm{Cl}$. (Lepidoptera, Geometridae) in oak forests - Šumarski list 134: 403-410.

HibBARD E. \& ElKINTON J.S. 2015: Effect of spring and winter temperatures on winter moth (Geometridae: Lepidoptera) larval eclosion in the northeastern United States. - Environ. Entomol. 44: 798-807.

Holliday N. 1977: Population ecology of winter moth (Operophtera brumata) on apple in relation to larval dispersal and time of bud burst. - J. Appl. Ecol. 14: 803-813.

Jepsen J.U., Kapari L., Hagen S.B., Schott T., Vindstad O.P.L., Nilssen A.C. \& Ims R.A. 2011: Rapid northwards expansion of a forest insect pest attributed to spring phenology matching with sub-Arctic birch. - Glob. Chang. Biol. 17: 2071-2083.

KAITANIEMI P. \& RUOHOMÄKI K. 1999: Effects of autumn temperature and oviposition date on timing of larval development and risk of parasitism in a spring folivore. - Oikos 84: 435-442.

Kerslake J. \& Hartley S. 1997: Phenology of winter moth feeding on common heather: effects of source population and experimental manipulation of hatch dates. - J. Anim. Ecol. 66: 375-385

Kimberling D.N. \& MilLeR J.C. 1988: Effects of temperature on larval eclosion of the winter moth, Operophtera brumata. Entomol. Exp. Appl. 47: 249-254.

Lodge D. 1993: Biological invasions - lessons for ecology. Trends Ecol. Evol. 8: 133-137.

MjaAseth R.R., Hagen S.B., Yoccoz N.G. \& Ims R.A. 2005: Phenology and abundance in relation to climatic variation in a subarctic insect hebivore-mountain birch system. - Oecologia 145: $53-65$.

Myking T. \& Heide O.M. 1995: Dormancy release and chilling requirement of buds of latitudinal ecotypes of Betula pendula and B. pubescens. - Tree Physiol. 15: 697-704.

Nilssen A. \& Tenow O. 1990: Diapause, embryo growth and supercooling capacity of Epirrita autumnata eggs from northern Fennoscandia. - Entomol. Exp. Appl. 57: 39-55.

Pimentel D., Lach L., Zuniga R. \& Morrison D. 2000: Environmental and economic costs of nonindigenous species in the United States. - Bioscience 50: 53-65.

Pöyry J., Luoto M., Heikkinen R.K., KuUsaari M. \& SaArinen K. 2009: Species traits explain recent range shifts of Finnish butterflies. - Glob. Chang. Biol. 15: 732-743.

RUономÄкI K., HANHIMÄKI S. \& HAUKIOJA E. 1993: Effects of egg size, laying order and larval density on performance of Epirrita autumnata (Lep., Geometridae). — Oikos 68: 61-66.
Ruohomäki K., TanhuanpäÄ M., Ayres M.P., Kaitaniemi P., TamMARU T. \& Haukioja E. 2000: Causes of cyclicity of Epirrita autumnata (Lepidoptera, Geometridae): grandiose theory and tedious practice. - Popul. Ecol. 42: 211-223.

Saikkonen K., Taulavuori K., Hyvönen T., Gundel P.E., Hamilton C.E., Vänninen I., Nissinen A. \& Helander M. 2012: Climate change-driven species' range shifts filtered by photoperiodism. - Nat. Clim. Chan. 2: 239-242.

SPEYER W. 1938: Über das Vorkommen von Lokalrassen des Kleinen Frostspanners (Cheimatobia brumata L.). - Arb. Physiol. Angew. Entomol. Berl. 5: 50-76.

Tammaru T., Tanhunanpää M., RUohomäki K. \& Vanatoa A. 2001: Autumnal moth - why autumnal? - Ecol. Entomol. 26: 646-654.

TENOw O. 1972: The outbreaks of Oporinia autumnata Bkh. and Operophthera spp. (Lep., Geometridae) in the Scandinavian mountain chain and northern Finland 1862-1968. - Zool. Bidrag Från Uppsala (Suppl.) 2: 107 pp.

Tenow O., Nilssen A.C., Bylund H., Pettersson R., Battisti A., Bohn U., Caroulle F., Ciornei C., Csóka G. \& Delb H. 2013: Geometrid outbreak waves travel across Europe. - J. Anim. Ecol. 82: 84-95.

TIKKANEN O. \& LyYtiKÄINEN-SAARENMAA P. 2002: Adaptation of a generalist moth, Operophtera brumata, to variable budburst phenology of host plants. - Entomol. Exp. Appl. 103: 123133.

Tikkanen O., Woodcock B., Watt A. \& Lock K. 2006: Are polyphagous geometrid moths with flightless females adapted to budburst phenology of local host species? - Oikos 112: 83-90.

Tomiczek C. \& Perny B. 2005: Aktuelle Schäden an Bäumen im Stadtbereich. - Forstschutz Aktuell 34: 2-6.

Valtonen A., Ayres M.P., Roininen H., Pöyry J. \& Leinonen R. 2011: Environmental controls on the phenology of moths: predicting plasticity and constraint under climate change. Oecologia 165: 237-248.

VAn Asch M. \& Visser M.E. 2007: Phenology of forest caterpillars and their host trees: the importance of synchrony. - Annu. Rev. Entomol. 52: 37-55.

Van Dongen S., Backeljau T., Matthysen E. \& Dhondt A.A. 1997: Synchronization of hatching date with budburst of individual host trees (Quercus robur) in the winter moth (Operophtera brumata) and its fitness consequences. - J. Anim. Ecol. 66: 113-121.

VAn Doorslaer W. \& Stoks R. 2005: Thermal reaction norms in two Coenagrion damselfly species: contrasting embryonic and larval life-history traits. - Freshw. Biol. 50: 1982-1990.

Vänninen I., Worner S., Huusela-Veistola E., Tuovinen T., NiSSINEN A. \& SAIKKONEN K. 2011: Recorded and potential alien invertebrate pests in Finnish agriculture and horticulture. Agric. Food Sci. 20: 96-114.

VisSer M.E. \& Holleman L.J. 2001: Warmer springs disrupt the synchrony of oak and winter moth phenology. - Proc. Biol. Sci. 268: 289-294.

Worrall J. \& Mergen F. 1967: Environmental and genetic control of dormancy in Picea abies. - Physiol. Plant. 20: 733745.

WYLIE H.G. 1960: Some factors that affect the annual cycle of the winter moth, Operophtera brumata (L.) (Lepidoptera: Geometridae) in Western Europe. - Entomol. Exp. Appl. 3: 93-102.

Received October 22, 2015; revised and accepted March 1, 2016 Published online April 22, 2016 